\title{
Refugee Women and the Integration into a New Society through Education
}

\author{
Djenita Svinjar ${ }^{1^{*}}$ \\ ${ }^{1}$ Djenita Svinjar is an independent researcher \\ "Correspondence: dsvin628@gmail.com
}

\begin{abstract}
This paper addresses various impediments and obstacles that refugee girls must surpass to obtain an education at the primary, secondary, and tertiary levels. It analyzes a variety of examples from across the world in order to portray the difficulties girls in these situations face on their quest to obtain higher education, and the responding initiatives certain programs and countries have implemented in order to better assist these women. This paper will further showcase how, worldwide, refugee girls and women are significantly disadvantaged in terms of access to education as shown by lower enrollment rates, and the statistical evidence indicating higher likelihoods to drop out. Nevertheless, this paper will address why, when presented with such statistics and probabilities, the women who overcome such adversity will become stronger-willed and resilient individuals whose capabilities and strengths can lead them to higher levels of success in life.
\end{abstract}

Keywords: refugee, women, international, education

\section{Introduction}

Picture a five-year-old refugee child sitting among her new classmates at a new school, in a new country, not understanding the language being spoken around her, reflecting on the hardships she has already witnessed at such a young age. Imagine the new world presented to her that she must try to comprehend moving forward. Unless one has personally experienced such obstacles, it is hard to imagine the daunting thoughts encapsulating this child's mind in those unfamiliar moments.

Received November 11, 2019; revised April 12, 2020, and October 1, 2020; accepted October 15, 2020; electronically published December 18, 2020

Journal of Comparative \& International Higher Education

December, 2020, Vol. 12, No. 3, pp. 140-153.

DOI: $10.32674 /$ jcihe.v12iWinter.1996

(C) 2020 Journal of Comparative \& International Higher Education. All rights reserved. 
Now, imagine that very child decades later if she continues on the path towards obtaining a higher education. At this point, it is assumed that the woman has integrated herself into the culture of her new home country following decades and numerous opportunities for assimilation. Furthermore, it is also assumed that by this point, this woman's character has undergone tremendous growth, given her personal history, experiences endured, and obstacles overcome in those preceding decades. Depending on the circumstances presented in the female refugee's pathway to obtaining a higher education, the impediments in her path inevitably encountered will also present a priceless sensation that will benefit her for years to come: pride. In fact, women who exhibit pride in themselves, their education, and their work product give themselves the opportunities to propel themselves forward by incorporating their training and education to "understand their rights and develop more self-confidence" (Survivors, Protectors, 2011, p. 7). It is this very assertion that evidences that refugee women who obtain a higher education benefit not only themselves, but society as well.

This paper will examine refugee girls' paths in obtaining an education. Rather than assessing from an empirical perspective, this paper will consider various sources in the context of a public policy perspective. Considerations will be given in comparing statistics from numerous countries, examining the reasons refugee girls generally trail behind in obtaining an education, and further reviewing the overall impacts education has on refugee women as a whole.

Part I- The Numbers Speak for Themselves: Refugee Girls are Inherently Disadvantaged in Terms of Obtaining an Education when Compared with Their Male Counterparts

To understand the foregoing conclusions set forth in the introduction, one must understand the history relating to refugee children's education. Refugee children not only have to endure the challenges that come with assimilating into a new culture, language barriers, fiscally and mentally draining situations within their families, but they also face harrowing statistics that many would argue work against them. For instance, "only 61 percent of refugee children have access to primary education, compared to an 
international average of 91 per cent. At secondary level, 23 percent of refugee adolescents go to school, compared to 84 percent globally" (United Nations, 2018, para. 15).

However, these statistics are even more troubling when discussing refugee girls' educations. In fact, "for refugee girls, it is even tougher to find - and keep - a place in the classroom. As they get older, refugee girls face more marginalization and the gender gap in secondary schools grows wider" (United Nations, 2018, para. 3). Furthermore, girls are much more likely to be significantly disadvantaged than boys not only when it comes to school enrollment, but also due to their higher likelihood to drop out after enrollment. Thus, "boys and men have a far greater chance of resuming their education once it has been interrupted by forced displacement than girls and women do, especially at the tertiary level" (Anderson, 2017, para. 4).

Why the disparity when comparing the two? Numerous considerations contribute to the gap between refugee boys and girls when it comes to their educations. Examples include economic obstacles facing families, and quite often, undervalued considerations for gender, with girls' challenges consistently being ignored or deemed an afterthought worldwide. This generally occurs due to the societal and cultural norms within various societies where a girl's place is believed to be in the home, rather than in a school. A larger problem contributing to the gap discussed is that many girls and women also encounter unsafe and unsupportive environments where they are more likely to be harassed or attacked. Global Coalition to Protect Education from Attack's 2018 Report showed that "girls and women were targets of attacks in educational settings or schools because of their gender in at least 18 of the 28 countries profiled" (Global Coalition, 2018, p. 28).

In considering the foregoing alarming statistics, one must assess the impact this has on refugee girls moving forward.

Part I(a): The Statistics, Explained 
The impact that forced migration has on women and girls is quite blatant. In situations where a war breaks out and families are forced to flock to nearby countries for safety, aspirations for a bright future and of a higher education can appear rather bleak. In an interview conducted in the "CoHe Academic Heritage Project" a Syrian woman, resettled in Turkey and currently studying at Istanbul University, reflected upon her experiences, stating the following: "I had a wonderful life before the war broke out in my country. I was studying English literature at university. I got married in my first year. Then the war broke out; when that happened, our lives were ruined. I had to leave my family, my loved ones, my school and move out from my country, my homeland" (Komsuoğlu, 2019, para. 8). Nevertheless, this woman overcame the foregoing hurdles and is currently enrolled at a university and continuing with her education. Unfortunately, more often than not, experiences such as hers are rare.

Such an example is evident with the humanitarian and refugee crisis recently arising out of Syria. In Syria alone, 5.6 million people have fled the country since the official beginning of the Syrian War in March of 2011 (Syria Refugee, n.d.). Along with displacement, Syrian children, particularly young girls, are consequentially facing other challenges including, but not limited to, sexual violence, child labor, and child marriage. According to a 2014 Save the Children Report, forced marriage among young Syrian refugee girls in Jordan doubled since the beginning of the Syrian War (Harvey, 2014). In Lebanon, $41 \%$ of young displaced Syrian women were married before 18 (Malala Fund, n.d.).

Many countries are working to assist refugees from the Syrian crisis with obtaining a legal status by utilizing means such as the 1951 Refugee Convention, or through individualized Memorandums of Understanding with the United Nations High Commissioner for Refugees (hereafter referred to as the "UNHCR"). The 1951 Refugee Convention is a multilateral treaty that not only sets forth the definition of a refugee, still utilized to this day, but also sets forth the rights of refugees and the responsibilities of host countries. 
In looking at the countries that Syrian refugees migrated to and the statistics therein, Turkey is one statistic that provides an obvious example of the stark distinctions between the genders, as it relates to education. In Turkey alone, $65 \%$ of Syrian men are pursuing a bachelor' degree, compared to only $35 \%$ of Syrian women (Hohberger, 2018, p.16). In other countries, such as Lebanon, Syrian refugee women face similar fates.

This begs the question of how countries and organizations can overcome such dire statistics and assist refugee girls and women with their educations moving forward.

\section{Part II: Overcoming the Statistics and Obstacles: The Path to Obtaining Higher Educations}

The key is getting started. In enrolling the girls into school, the consequences forming thereafter are undeniable. In fact, according to the World Bank, "if all girls completed primary education then child marriage would fall by 14 percent, while finishing secondary education would see that figure fall by a massive 64 percent. Research shows that educated mothers are more likely to send their children especially girls - to school, and that one additional year of education can boost a woman's earnings by up to a fifth" (United Nations, 2018, para. 7).

The problem is addressing how to go about getting started. While numerous countries and international organizations and agencies worldwide have taken steps to address the problems relating to refugee education, particularly, refugee girls' education, few country governments have taken steps toward remedying the existing problems evident today. This leaves the burden on specific organizations to attempt to discern the problems relating to the refugee educational crisis. As evidenced by their 2019 pledge, the UNHCR "pledged to help expand secondary education to at least one million refugees. Nongovernmental organizations such as the Inter-Agency Network for Education in Emergencies, Education International, and Jesuit Refugee Service have also pledged support for secondary education"

(Small, 2020, para. 5). However, these organizations cannot go it alone without assistance and cooperation from host governments. 
In addition, problems lie with the educational programs themselves as it relates to assisting the refugee children with the overall transition. The disconnect with host country education systems and incoming refugee students arises from a limited understanding as it relates to the needs of refugee students, particularly female refugees (Education Integration, n.d.). Without the mutual cooperation and assistance of governments of countries hosting refugees, and associated agencies and departments, little can be effectuated.

Solutions can be implemented to assist refugee children with self-sufficiency as it pertains to their educational journeys. For example, a "cultural understanding when interpreting/evaluating transcripts is needed to institute better testing that will result in more accurate and appropriate placement" (Education Integration, n.d., para. 8). Better communication between local governments and schools, implementing guidance counseling to assist with the overall transition, and educating refugee families along with the children are all tactful approaches to help with refugee resettlement, and education transitions for refugee children, especially for refugee girls.

When such coordination is implemented and systems are effectuated that can home in on assisting refugee girls with their educations, both society and the girl reap the benefits.

\section{Part III: Refugee Women's Higher Educations Improve Society and Consequently, Help the Women}

\section{Themselves}

Historically and statistically speaking, refugees have positively impacted the new countries they settle in by contributing "billions of dollars each year to the economy through consumer spending and business start-ups, resulting in a net positive fiscal impact", revitalizing otherwise dwindling areas into vibrant areas, nationwide, and benefiting the economy through the workforce (Immigrants as, 2018, para. 2). This is particularly prudent to reflect upon, especially when it comes to refugee women and the lessons and work ethics they bring with them. 
Numerous sources show that "highly-educated female refugees have the potential to become leaders and role models both in their home and host communities. Furthermore, the key role of educated women in raising children is also undeniable" (Komsuoğlu, 2019, para. 3). Educated women are far more likely to send their children to school, advocate for the success of their children, and understand the significance a degree has nowadays, as well as the doors that very degree can open for their children.

In addition, the social benefits bestowed upon refugee girls who obtain an education are undeniable. According to a 2018 publication done by the World Bank, "universal secondary education for girls could increase the ability of women to engage in altruistic behaviours, and their ability to rely on friends when in need. It could also increase their ability to assess institutions and services" (Missed Opportunities, 2018, para. 9). Providing a young girl access to education early on inevitably benefits her in the social realm by allowing her to discover her interpersonal skills when interacting with peers and allowing her to develop a sense of identity around children who may or may not be like her. For example, a refugee girl that enters a classroom with other children, both refugees and non-refugees alike will immediately benefit from the diverse atmosphere she has entered into by learning about, and from, children that may or may not be like her. Even if the refugee girl is placed into a classroom with solely other refugee children, that particular child will still benefit from the social interactions in being around children who have similar backgrounds, but undeniably, different individual experiences.

However, aside from the social benefits discussed above, other benefits are also reaped when refugee girls obtain educations. Going to school provides a routine for these girls, and it provides "normality, purpose, and time away from the pressures and burdens of refugee life - important for all girls and boys but in some cases especially so for girls, who are vulnerable to exploitation and to sexual and gender-based violence" (Grandi, n.d., para. 9). In this perspective, school provides a solace for these girls, and a getaway from the troubles they, and their families, may be experiencing in assimilating and leaving their countries. Furthermore, not only does education present an opportunity to forget their past 
and present troubles, if only for a moment, but it also "enables refugees, particularly women and girls, to gain the knowledge and skills that would allow them to engage in public spaces and paid employment, and thus to enhance their equality and independence" (El Jack, 2010, p. 23). When women who are generally accustomed to being deemed inferior to men are educated, they gain a sense of independence that they otherwise would not have had. This not only presents a feeling of individualism, but it serves as a motivating factor to the women in continuing their personal journey onward, with or without the assistance of a man.

In addition to the social benefits education provides, health and physical benefits are also reaped. A 2016 UNHCR education report emphasized such benefits even further, stating that education allows refugee children the ability to learn about "basic health care and hygiene, citizenship, human rights and where, how and from whom to get help. From the first lessons through to university, education helps refugees stand on their own feet, allowing them to prepare for the future, whether that is in a host country or in their own country upon their return" (United Nations, 2016, para. 10).

Delving even further in considering the health implications forced migration has on both girls and women, numerous sources have discussed the long-term impacts resettlement has on females. In particular, girls' and women's reproductive systems can be especially impacted due to the lack of health services available to these females (Johnson, 2011). If girls were enrolled in education systems from an earlier age, not only would they have a larger perception to some of the above-mentioned issues, but they would indisputably have access to more resources that could assist them during such distressing experiences.

The values discussed above are those that will be promptly reaped once the girl is enrolled in school. However, one must also consider the long-term benefits and impact an education will have on a refugee girl years later when she becomes an established woman that has long since assimilated into her host country. 


\section{Part III(a): Growing Up and Growing Out}

Refugee women who have obtained higher educations in their host countries arguably have faced more adversity and overcome more challenges than many of their counterparts. As a result, not only are they able to take pride in the obstacles they have overcome to date, but they can take pride in the individual they have become as a result of the hardships they encountered.

Unfortunately, recent statistics evidence that those who obtain a college education appear to be the slim minority. According to a UNHCR Education Report conducted in 2016, "[t]o reach university education level, a young refugee has to overcome significant barriers and only one in 100 makes it. By comparison, just over one-third of young people of university age around the world are in tertiary education" (Aiming Higher, 2016, para. 1). In other words, non-refugees have 33 times more of a likelihood to obtain a higher education than their refugee peers. This gap is further widened when considering the likelihood that a refugee woman obtains a college degree. Nevertheless, in homing in on the women who do obtain a higher education, the results speak for themselves. These women are more confident, prideful, and resilient. They can appreciate their experiences, understand the value of their educations, and resonate with other refugees as a whole.

Take for example a 2018 article published in the Salt Lake Tribune which speaks of refugee women from various countries (including Afghanistan, Iraq, Sudan, Kuwait, Somalia, India, Congo, and the Central African Republic) and their successes as refugees in the US (hereafter referred to as the "Salt Lake Article"). The Salt Lake Article discusses how each of the women being honored at the award ceremony were celebrated for individual accomplishments, including finishing high school and learning English. In turn, the women who completed their education flourished and remained persistent.

One such honoree, a 21-year-old at the awards ceremony had fled Sudan with her family. She came to the US, completed high school, currently takes classes at the local community college, works at a nursing home and aspires to become a dentist (Stack, 2018). Of course, the girls and women discussed in 
this article also spoke of bearing witness to their families' struggles in their new country and the hardships and persistence they witnessed, which may factor into such motivations and success stories. Nevertheless, the education and training they received inevitably attributed to their success stories to date, and their successes that are to come. The aforementioned ceremony, established and organized by Women of the World, an organization dedicated to providing support and education to refugee women and their families, hosts such events every December, where they pay homage to refugee women within their communities and their individual paths to self-resilience (Developing Community, 2019). The examples they provided of the women being recognized, in relevant part, highlight the stories of such women:

- Ana- a young woman beginning college in 2020 , dedicated to finding a career to helping others. In the meantime, she helps take care of her siblings.

- Kurdet- a woman who completed medical school in Turkey, fled her country, relocated to the US and passed three medical exams to obtain her license in Utah. Kurdet is heavily involved with her community in her new home of Utah.

- Luma- a woman from Iraq with a computer science degree who has focused on learning English to prepare for entry into college. She currently works as a teacher and is the caretaker for her young children.

- Mwamini- a young girl applying for scholarships to allow her the opportunity to go to college. Not only has she persistently worked on her English, but her past successes include starting an African American Association at her school and obtaining good grades in school (Developing Community, 2019).

The examples listed above show an unquestionable correlation to education and success. Each of the women identified has either obtained a level of high school education or higher, is actively pursuing a college degree, or has completed a form of graduate school. In the interim, they are focused on outside successes and productivity as well. They are concurrently raising their families, being involved in the 
communities, and serving as inspirational sources for others who may have parallel stories and backgrounds. Not only have they showcased their resiliency through their accomplishments, but their pride in such resiliency is heartfelt when reading about their past successes, and their intended goals as well.

On the other hand, one must also consider the repercussions of not enrolling refugee women and girls in educational institutes in their new countries. As touched upon in the Salt Lake Article, the countries that many of the women hail from have a culture in which the woman is tasked with the job of being a nurturer, for both her husband and children. These women seldom, if at all, are able to leave the home without their husbands or another male companion. As a result, many of the women in these countries are not as educated as the men and accordingly, are not able to prosper in ways they otherwise would if they were formally educated. Interestingly, the Salt Lake Article also touches upon another intriguing facet that many fail to consider when discussing refugee women and their plight in obtaining a formal education. The Salt Lake Article brings up the point that if these women are forced to stay at home, not only are they isolated and disconnected from their new culture and language, but they are having to rely on their children, and the English the children are learning in their schools in order to get by (Stack, 2018).

Given the aforementioned examples, it is obvious that female refugees who are provided access to higher education can improve their lives, their family's overall wellbeing, and their surroundings and communities. In the future, they may even be able to assist their homelands and the people still residing there through outreach efforts.

\section{Part IV: Conclusion}

In sum, refugee girls and women who obtain higher levels of education reap immeasurable benefits from doing so. Additionally, they take pride in their journey and the individuals they have become because of said journey. This, in turn, benefits the women themselves, their communities, their host countries, and younger generations who can look to such women as sources of inspiration. 


\section{Author Note}

Djenita Svinjar came to the US as a child refugee in 1994 during the Bosnian War. She obtained her BA in Philosophy/ Pre-Law from St. Bonaventure University and her JD from UIC John Marshall Law School. She is Corporate Counsel for Hensel Phelps Construction Co. In her free time, Djenita sits on the boards of the Bosnian American Genocide Institute and Education Center and the Boys and Girls Clubs of Weld County in Colorado.

\section{References}

Aiming Higher - The other one per cent. (2016). UNHCR. https://www.unhcr.org/en-us/aiminghigher.html.

Anderson, A., \& Bix, M. (2017, June 7). Aiming higher: Prioritizing higher education within the global movement for refugee education - Refugee education. Promising Practices in Refugee Education. https://www.promisingpractices.online/news/2017/6/5/aiming-higher-prioritizinghigher-education-within-the-global-movement-for-refugee-education

Developing Community thru Achievements in Self-Reliance. (2019, December 28). Women of the World. https://www.womenofworld.org/blog/developing-community-through-achievements-in-selfreliance

EDUCATION Integration Barriers: Perspectives from Refugee Youth. (n.d.). Bridging Refugee Youth \& Children's Services. https://brycs.org/schools/education-integration-barriers-perspectives-fromrefugee-youth/ 
El Jack, A. (2010). Education is my mother and father: The "invisible" women of Sudan. Refuge: Canadian Journal on Refugees, 27(2), 19-29. https://refuge.journals.yorku.ca/index.php/refuge/article/view/34719/31549

Global Coalition to Protect Education From Attack. (2018). Education Under Attack 2018. http://protectingeducation.org/wp-content/uploads/documents/documents_eua_2018_full.pdf

Grandi, F. (n.d.). HER TURN: It's time to make refugee girls' education a priority - UNHCR. UNHCR. https://www.unhcr.org/herturn/

Harvey, C., Garwood, R., \& El-Masri, R. (2014, July 14). Shifting Sands. Oxfam International. https://www.oxfam.org/en/research/shifting-sands

Hohberger, W. (2018, March). Opportunities in Higher Education for Syrians in Turkey. Istanbul Policy Center. https://ipc.sabanciuniv.edu/Content/Images/Document/turkiyedeki-suriyeliler-icinyuksekogretim-imkanlari-3980cb/turkiyedeki-suriyeliler-icin-yuksekogretim-imkanlari3980cb.pdf

Immigrants as Economic Contributors: Refugees Are a Fiscal Success Story for America. (2018, June 14). National Immigration Forum. https://immigrationforum.org/article/immigrants-as-economiccontributors-refugees-are-a-fiscal-success-story-for-america/

Johnson-Agbakwu, C. (2011). Women's Health. Refugee Health Technical Assistance Center. https://refugeehealthta.org/physical-mental-health/health-conditions/womens-health/

Komsuoğlu, S. (2019a, March 5). Syrian women's access to higher education in Turkey. European University Association. https://eua.eu/resources/expert-voices/89:syrian-women\%E2\%80\%99saccess-to-higher-education-in-turkey.html.

Komsuoğlu, S. (2019b, March 5). Syrian women's access to higher education in Turkey. European University Association. https://eua.eu/resources/expert-voices/89-syrian-women\%E2\%80\%99saccess-to-higher-education-in-turkey.html 
Malala Fund. (n.d.). Syria Region / Malala Fund. Retrieved February 5, 2020, from https://malala.org/programmes/syria-region

Missed Opportunities: The High Cost of Not Educating Girls. (2018, July 11). World Bank. https://www.worldbank.org/en/topic/education/publication/missed-opportunities-the-highcost-of-not-educating-girls

Small, B. (2020, July 10). Refugee Children Have the Right to a Full Education. Human Rights Watch. https://www.hrw.org/news/2019/12/16/refugee-children-have-right-full-education\#

Stack, P. (2018, December 9). Better than an Oscar: Refugee women in Utah recognized for self-reliance and individual accomplishments. The Salt Lake Tribune. https://www.sltrib.com/religion/2018/12/09/refugee-women-recognized/

Survivors, Protectors, Providers: Refugee Women Speak Out. (2011, November). The UN Refugee Agency. https://www.unhcr.org/4ec5337d9.pdf

Syria Refugee Crisis Explained. (n.d.). UNHCR The UN Refugee Agency. Retrieved February 1, 2020, from https://www.unrefugees.org/news/syria-refugee-crisis-explained/ United Nations High Commissioner for Refugees. (2016). Starting Out - Why education for refugees matters. UNHCR. https://www.unhcr.org/en-us/starting-out.html.

United Nations High Commissioner for Refugees. (2018, March 7). Her Turn: UNHCR report reveals critical gap in education for refugee girls. UNHCR. https://www.unhcr.org/enus/news/press/2018/3/5a9eb2024/turn-unhcr-report-reveals-critical-gap-education-refugeegirls.html

United Nations High Commissioner for Refugees, Dunmore, C., \& Sakkab, A. (2018, March 6). School offers Syrian girls in Jordan the chance to flourish. UNHCR. https://www.unhcr.org/enus/news/stories/2018/3/5a9ec9ad4/school-offers-syrian-girls-jordan-chance-flourish.html 